\title{
La re-creación de la realidad en los «reality shows»
}

The re-creation of reality in reality shows

María del Pilar Grela Barros, Universidade de Santiago de Compostela - piligrela@gmail.com

Xoel López Penido, Universidade de Santiago de Compostela - xoel.lopenido@gmail.com

Marta Pérez Pereiro, Universidade de Santiago de Compostela - marta.perez.pereiro@usc.es

\section{Resumen}

Desde la aparición de los primeros reality shows, el formato ha ido ganando presencia en las parrillas televisivas hasta convertirse en el protagonista de la televisión. El formato ha sufrido hibridaciones y transformaciones que, en muchos casos, lo conducen al uso de estructuras formales propias de la ficción para crear historias, y lo alejan de la realidad que suponemos su punto de partida. Analizaremos en este trabajo, pues, el grado de ficcionalización del formato. Además, el trabajo analiza la tendencia hacia lo hiper de la televisión actual y la recepción del reality show en la sociedad contemporánea. La metodología empleada consistirá, en primer lugar, en abordar bibliografía relacionada con el tema para establecer un marco teórico y, como eje del artículo, estudiaremos las últimas ediciones de Gran Hermano (GH), Un Príncipe Para... (UPP) y Los Gipsy Kings (LGK) en base a fichas de análisis que contemplan tanto elementos narrativos propios de la ficción, como estructuras específicas de los formatos, así como vinculaciones con el universo real del que parten. Para triangular nuestras conclusiones, contaremos con una serie de entrevistas a expertos y profesionales del sector, y con la visión de dos grupos de discusión conformados por consumidores de reality shows.

\section{Palabras clave}

Reality show, televisión, narrativa, espectáculo, simulacro.

\section{Abstract}

Since the appearance of the first reality shows, this format has been gaining presence in the schedule and has a leading role in the TV offer. At the same time, reality TV has suffered some hybridizations and transformations, which have placed it closer from the use of fictional structures in order to create stories and far from the reality that is supposed to be its starting point. In this paper we will analyze the degree of fictionalization of the format. Besides, this paper analyzes the trend towards the hyper in current television and the reception of the reality show in contemporary society. The methodology is divided in three parts. On the one hand, we are going to accost some relevant authors about this theme to define a theoretical framework. On the other hand, we will analyze three programs: Gran Hermano, Un príncipe para tres princesas and Los Gipsy Kings. We are going to use an analysis sheet which includes some fiction characteristics, others exclusive for this format, as well as their linkages with the real world. Finally, our conclusions will be compared with the opinion of experts and professionals in the sector, and the impressions of consumers of reality TV.

\section{Keywords}

Reality show, television, narrative, show, simulation.

Sumario

1. Marco teórico. 2. Metodología. 3. Resultados. 4. Discusión y conclusiones. 5. Referencias bibliográficas. 


\section{Marco teórico}

En La era del vacío, Lipovetsky (1986) señalaba que la cultura espectacular propia de nuestro tiempo se basa en la exigencia de dramatización, emoción y estimulación constantes. La televisión, uno de los medios de comunicación contemporáneos por excelencia, atiende a esta demanda mediante la puesta en relato de la actualidad.

Varios autores (Cáceres, 2010; Imbert, 2004; Zunzunegui, 2009) apuntan, además, que una de las principales características adoptadas por la televisión de nuestro tiempo es la de dar presencia reiterativa e invasiva a contenidos basados en la realidad cotidiana, hasta el punto de que sus cámaras se han convertido en cámaras de vigilancia cuya función es penetrar en la intimidad de los sujetos. Cualquiera puede convertirse en actor, y cualquier acontecimiento, por banal que sea, es susceptible de ascender al rango de historia que merece ser contada, de espectáculo que merece ser contemplado (Zunzunegui, 2008: 136-7; citado en López, 2009).

De este modo, la televisión se erige como un medio que se dedica a hacer-ver, a dar forma a lo informe. Vuelve significante lo insignificante, visibiliza lo invisible (lo íntimo, lo secreto, lo tabú), impone la conversación sobre la representación (Bettetini, 1986; Postman, 1991; Darley, 2002; citado en Imbert, 2004) y la exhibición sobre la comunicación, en un acto redundante en el que el espectáculo es principio y fin.

Lejos de limitarse a dar prioridad a este tipo de contenidos, «es propio de la televisión contemporánea el buscar nuevas fórmulas a través de las cuales establecer relaciones inmediatas, intensas y emotivas con sus públicos» (Chicharro, 2008). Dichas fórmulas implican cierta dramatización de la realidad que, en muchos casos, conlleva una re-creación de esa realidad con el objetivo de que este simulacro resulte más espectacular que la realidad misma.

Roland Barthes (citado en Normand, 2015) definió el lenguaje como un sistema simbólico que hemos aceptado para poder comunicarnos en tanto designa la realidad, pero que nunca podrá ser la realidad misma, y esto puede extenderse al formato audiovisual, otro sistema simbólico que aceptamos por convención, pero que nunca podrá ser una ventana objetiva hacia una realidad absoluta.

Lo que distingue al régimen audiovisual de nuestros días tiene que ver con el hecho de que en él, el acontecimiento sustituye al relato, el hecho eclipsa a la comunicación y el presentador suplanta al narrador. «En resumen, la imagen ya no imita, se fusiona con lo real» (Zunzunegui, 2009: 8), y a través del uso de estructuras formales propias de la ficción, procede a la reconstrucción «fidedigna» de un suceso.

Al respecto, apuntaba Bauman en Modernidad Líquida (2000) que al crear relatos, el deseo de la revelación y las revelaciones del deseo les otorgan apariencia de autenticidad, es decir, verosimilitud, aún cuando es la posibilidad de dicha autenticidad lo que está en entredicho. Muchas veces, esto conduce a sustituir la verdad de los hechos por la verosimilitud de lo que se cuenta, y a dar relevancia a los contenidos televisivos por el mero hecho de serlo, relegando a un segundo plano los criterios de verdad presentes en los mismos. En palabras de Imbert (2003; citado en Gómez y Ramiro, 2005), «lo que hace creíble el mensaje es menos su verdad objetiva que el efecto de realidad que produce», lo cual, para González Requena (1992; citado en Castelló, 2004: 92), es «síntoma y consecuencia de la expansión espectacular televisiva».

De hecho, muchos de los programas que podríamos clasificar dentro del formato objeto de estudio en esta investigación, los reality shows, ni siquiera buscan representar la realidad, sino simplemente ofrecer una impresión realista en cierto grado, tal y como explica Normand (2015), que se mueve entre los límites de la realidad y lo verosímil.

Para Menéndez (2010), los medios de comunicación deciden qué realidad van a ofrecer desde el momento en que seleccionan unos fragmentos de la realidad para ofrecérselos al público en lugar de otros igualmente válidos que, no por dejar de aparecer en pantalla, dejan de formar parte de la realidad. Es decir, «la realidad ofrecida por los medios no es la única, sino que constituye una parte ínfima de la realidad social» (Menéndez, 2010: 231), y en ella van implícitos, de un modo u otro, los intereses de quien la pone en imagen. Incluso en la aparente pureza de las imágenes del directo existe cierta mediación.

Martín Serrano (2004; citado en Cáceres, 2010) diferencia dos tipos de mediación: la cognitiva y la estructural. La primera hace referencia a la tarea de selección entre todos los datos posibles para transmitir determinada información a la audiencia, es decir, es relativa al contenido. La segunda, sin embargo, apela a la necesidad de llevar a cabo cierta elaboración profesional en la narración que se transmite al espectador, es decir, es relativa a la forma. Visto lo anterior, podemos secundar la afirmación de Cáceres (2010) cuando dice que la vida cotidiana televisada tiene la característica de ser sometida a una re-creación que la convierte en espectáculo mediático. Dicha recreación es la consecuencia de atravesar el filtro del lenguaje televisivo que, como hemos visto, produce significados no exentos de intereses concretos. Para Bignell (2004), la clave del lenguaje del realismo televisivo está en la interacción entre lo que aparece en televisión y el modo que tiene la audiencia de percibirlo, que permite establecer entre ambas partes un pacto mediático del que hablaremos más adelante.

Parece lógico concluir que toda historia de realidad debe ser encauzada a través de una serie de parámetros, tanto para que tenga sentido como para que sea de interés. Si además, como apunta Iván Bort (2009), esta historia de realidad se desarrolla en un escenario preconfigurado, nada de lo que en ella suceda es susceptible de considerarse completamente real, veraz, o puramente objetivo, sino que debe entenderse como un pseudoevento: la invención del acontecimiento para después contarlo (Bort, 2009: 4).

Por todo ello, más que la realidad que reflejan estos programas, en la presente investigación nos interesa la realidad que crean. «En una sociedad en la que la más elevada función del signo es hacer desaparecer la realidad y enmascarar al mismo tiempo esa desaparición» (Vázquez Medel, 2009: 18), la idea baudrillardiana del simulacro se erige en medular. El pensador francés define la simulación como «la generación por los modelos de algo real sin origen ni realidad: lo hiperreal» (Baudrillard, 1978: 5). No se trata de imitación ni de reiteración, sino de una suplantación de lo real por los signos de lo real en la que lo real, en palabras de García Martínez (2008), «se diluye, queda borroso, escondido tras un magma semiótico». Baudrillard (1978) prosigue en el desarrollo del concepto y apunta que se trata de «una disuasión de todo proceso real por su doble operativo. Al 
contrario que la utopía, la simulación parte de la negación radical del signo como valor, eliminando toda referencia en plena conciencia del juego y del artificio» (Baudrillard, 1978: 13).

Autores como como Imbert (2003) trasladan este concepto a nuestros días para aplicarlo a la televisión actual. En este caso, para señalar que la lógica de los medios ha pasado a ser reproductiva (en tanto pretendía imitar la realidad) a ser una lógica del simulacro (que pretende rivalizar con la misma) (Imbert, 2003). "Lo que nos muestran los medios contemporáneos no es, por tanto, ni verdadero, ni falso, sino un simulacro de la cotidianeidad en tanto realidad recreada en laboratorio» (Imbert, 2003: 203). García Martínez interpreta este fenómeno de la televisión actual:

La tendencia que hemos acuñado como postelerrealidad [hipertelevisión, en nuestro caso, siguiendo a Gordillo (2009)] no cesa de explorar nuevas vías expresivas mediante la exageración de los espejos deformados (u opacos) del simulacro y el estiramiento de la noción de performatividad. Es probable que, en los próximos años, el género de la «televisión de lo real» continúe mutando y ofreciendo nuevas propuestas hibridas que reflexionen implícitamente sobre cómo «autenticidad», «realismo» y «verdad» están siendo distorsionados, cuestionados y reinventados una y otra vez. (García Martínez, 2008: 12).

\section{Metodología}

La metodología propuesta consiste en el análisis de tres reality shows a través de unas fichas de elaboración propia. Los programas objeto de estudio son Gran Hermano (17) (Zeppellin, 2000-...), Un Príncipe para 3 Princesas (Cuatro Cabezas, 2013-...) y Los Gipsy Kings (3) (La Competencia, 2015-...), tanto por su excelente acogida por parte de la audiencia, como por tratarse de tres productos que, aunque son reality shows, pertenecen a subformatos diferentes. Esta circunstancia nos permitió establecer similitudes y contrastes entre ellos. Otras razones para dicha selección fueron la mayor accesibilidad a los contenidos y la actualidad de los mismos por su proximidad temporal, lo cual les otorga mayor validez a la hora de representar el fenómeno reality en el panorama televisivo nacional de nuestros días.

Para analizar dichos programas, elaboramos personalmente unas fichas que contemplan los elementos en los que queremos focalizar, además de reflejar aspectos de producción o audiencias que nos pareció relevante subrayar. En la parte central de dichas fichas, llevamos a cabo una distinción entre los elementos que acercan estos programas a la realidad y aquellos que los alejan de ella. En este segundo aspecto, el que más nos interesa subrayar, establecemos una nueva distinción entre aquellos elementos que tienen que ver con la forma y los que tienen que ver con el contenido, y dentro del apartado formal, establecemos otra distinción entre los elementos propios de la ficción y los característicos del formato reality.

Pese a considerar que las fichas que hemos elaborado recogen aspectos clave para el objetivo de la investigación, nos pareció fundamental triangular nuestros resultados con la opinión de consumidores de estos formatos y de expertos en la materia. Por ello, para obtener unas conclusiones operativas y útiles, nos pusimos en contacto con expertos en el medio televisivo, bien por su labor investigadora o docente, bien por estar desarrollando su actividad laboral en este ámbito de manera profesional. De este modo entrevistamos a ocho personas con diferentes perfiles: Ana Isabel Rodríguez, docente en la Universidad de Santiago de Compostela; Enrique Castelló, docente en la Universidad de Santiago de Compostela; Felipe Rodríguez, guionista en Supervivientes (Bulldog Producciones) y GH VIP; Jacobo Eireos, creador y director de LGK; Noelia del Río, directora de GH 17; Paula Cons, directora de Cuestións Persoais (Agallas Films, 2015-...); Raúl García, docente en la Universidad de Santiago de Compostela y guionista de Casamos (Grupo Progreso y Zenit, 2011-...); y Vicente F. Cabodevila, guionista de UPP3P. Persiguiendo el objetivo de sacar el mayor provecho de las entrevistas planteadas, decidimos elaborar cuestionarios personalizados y adaptados a la trayectoria de cada uno de ellos, motivo por el cual también consideramos oportuno emplear entrevistas flexibles, no estructuradas, permitiéndonos un abordaje transversal y más dinámico de las mismas.

Por último, y dado que los formatos televisivos se retroalimentan de sus espectadores, consideramos oportuno realizar dos grupos de discusión con consumidores de realities para obtener conclusiones sobre su modo de entenderlos. A la hora de seleccionar a los componentes de los grupos, tuvimos en cuenta que en esta investigación queremos ahondar en el hecho de que, desde la primera edición de $\mathrm{GH}$ hasta la última, el universo reality ha cambiado profundamente, y también su percepción. Por esta razón, contactamos con diez jóvenes de entre 21 y 23 años que consumen realities con asiduidad, pues su punto de vista es el de telespectadores que han crecido de la mano de la evolución del formato. Por otra parte, y para romper con el estigma que asocia el consumo de realities con la falta de formación académica, todos nuestros colaboradores son estudiantes universitarios.

\subsection{Hipótesis}

Partimos de tres hipótesis que pretendemos demostrar a lo largo de la presente investigación. La primera de ellas tiene que ver con las características del formato en el que nos centramos, el reality show, y sostiene que, pese a su supuesto referente en la realidad, los reality shows presentan estructuras formales propias de la ficción, así como un guion del propio formato que los aleja de dicho referente.

La segunda está relacionada con los cambios que lleva sufriendo el medio televisivo desde los años 80, momento en el que Eco (1986) y Casetti y Odin (1996) sitúan el nacimiento de la neotelevisión, separándose de la etapa anterior, la paleotelevisiva. Así como sostiene que la mutación en la forma de hacer y consumir televisión indica un cambio de tendencia hacia lo hiper.

La tercera hace referencia a la contribución de los reality shows a la sociedad y a la percepción de los mismos por parte de los telespectadores y la crítica, proponiendo que los realities son una opción televisiva de entretenimiento tan válida como cualquier ficción, y su consumo no tiene por qué resultar nocivo siempre que se comprenda que lo que aparece en pantalla no es un reflejo de la realidad, como se asume al ver una película de ficción. 


\section{Resultados}

Antes de empezar a comparar las características que hemos extraído de unos y otros programas, cabe destacar que, aunque los tres pertenecen al macrogénero de la telerrealidad y al formato reality show, los subformatos en los que los hemos clasificado son diferentes. GH es un docu-realityshow-game (abreviado como docu-game) pues combina la vigilancia de los personajes en directo durante 24 horas, con el formato concurso por un premio en metálico. UPP es un dating show, en tanto el hilo narrativo avanza a través de las citas entre concursantes, y también presenta carácter de concurso, pero en este caso el premio no es material, sino que el ganador será el aspirante a príncipe que logre conquistar a la princesa; LGK es un docu-reality, ya que sigue y muestra la vida de sus protagonistas, y en este caso no está presente el factor game, es decir, no tiene parte de concurso, sino que el objetivo es transmitir la subjetividad de esas personas bajo una estructura narrativa.

Por otro lado, hay una característica común a los tres realities, y es que todos son emitidos por el macrogrupo de comunicación Mediaset España, conocido por el éxito de sus realities que, siguiendo a nuestros entrevistados, responde a tres factores. La primera clave sería lo que Noelia del Río, denomina «cebos», piezas de montaje que anticipan al espectador lo que podrá ver a continuación si se mantiene fiel a la emisión. El segundo factor lo señalan tanto Ana Isabel Rodríguez, como Felipe Rodríguez: la elevada autorreferencialidad entre los diversos programas y espacios del macrogrupo. La tercera clave la aclara Raúl García, que señaló que en Mediaset «hacen como nadie telenovelas de realidad», refiriéndose a la capacidad del macrogrupo para conectar con el espectador al transmitirle historias con abundantes puntos de giro basadas en experiencias reales.

\subsection{Cuota de pantalla}

Los programas que hemos analizado presentaron las siguientes cuotas de pantalla: en el caso de GH, emitido por Telecinco, 19.68\%; UPP, emitido por Cuatro, registró un 7.2\%; y LGK, también de Cuatro, se posicionaron en un $11.5 \%$ de share. Las diferencias entre estos datos son, en parte, debidas a la cadena de emisión de los programas, pero también hay que contemplar el número de edición analizada en cada caso, pues cuanto mayor sea este, mayor será el número de televidentes fieles al programa: GH cuenta con un público consolidado desde el año 2000, lo cual justifica su liderazgo; LGK presenta una cuota de pantalla elevada si tenemos en cuenta que sólo lleva en emisión desde 2015, razón de que fuese trasladado a prime time después de mejorar sus datos temporada tras temporada. UPP presenta la cuota de pantalla más baja de los tres programas, pero en línea con la del canal en el que se emite, Cuatro, que presentó en su último ejercicio un $6.1 \%$ de share frente al $14.4 \%$ de Telecinco, cadena líder del país. En tercer lugar, existe un factor que, junto con los otros apuntados justifica que GH sea, de los tres programas, el que mejores datos de audiencia presenta: el directo. Parte de los espacios de GH son retransmisiones y conexiones en directo con la casa. Muchas veces, durante las mismas, Jorge Javier Vázquez apela al espectador para que, mediante sus votos (sean telefónicos, por SMS o a través de la app), cambie el curso de los acontecimientos del programa, lo cual supone un reclamo para el público a la hora de seguir el programa en el mismo momento de su emisión y no a través de plataformas de video on demand. Por el contrario, los otros dos programas son fruto de un trabajo de edición que elimina el factor directo.

\subsection{Plató, galas y papel de los presentadores}

La presencia o ausencia de espacios de plató intercalados con la historia que cuenta el reality es otro aspecto importante, ya que permiten conectar el programa con la audiencia, además de suponer un claro anclaje a la realidad. De los tres programas, el único que cuenta con un plató es $\mathrm{GH}$. Además, la celebración de Las Galas en el mismo, pese a irrumpir en la diégesis de la historia que narra el programa, permite que este avance, en tanto se produce la expulsión de alguno de los personajes. Esto último, aunque sin plató, también sucede en UPP, que comparte con GH la parte de la expulsión. En LGK, en cambio, no hay ni plató, ni galas, sino que las cuatro tramas principales se desarrollan de forma paralela hasta su desenlace en el último capítulo, de modo que la presentadora tiene la única función de hilar las distintas secuencias a través de su voz en off, sin aparecer físicamente en el programa.

\subsection{Referencias a la realidad}

En primer lugar, cabe señalar que todos los personajes que aparecen en estos programas son reales, así como lo son sus reacciones ante las situaciones que viven ante las cámaras. También lo son los lugares en los que se desarrollan los acontecimientos, pero con matices. Tanto en UPP como en LGK, los escenarios en los que se desarrolla la acción son identificados con rótulos que permiten anclar la historia a la realidad y, en el caso de GH, la audiencia sabe que la casa se encuentra en Guadalix de la Sierra. Sin embargo, tanto en GH como en UPP, se parte también de la existencia de escenarios preconfigurados, un rasgo que caracteriza a muchos programas de este formato. Estos serían, respectivamente, la casa de GH como entorno irreal, en tanto que completamente aislado del exterior, y el Reino de las Tres Coronas de UPP, que equivaldría a un espacio cinematográfico imaginado, en tanto se rueda en un lugar real, Málaga, pero se hace creer que es otro distinto.

Por otra parte, en los tres programas se realizan múltiples referencias a la actualidad y al contexto sociocultural del momento, que permiten al espectador ubicar el programa en un presente que consigue identifica. Esta referencialidad se refuerza a dos niveles, de nuevo, en los tres casos: en primer lugar, por los cameos de personajes conocidos, y, en segundo lugar, por la autorreferencialidad entre unos y otros programas del macrogrupo: en GH, los colaboradores de Las Galas y Debates son, por lo general, exconcursantes y protagonistas de otros programas de Telecinco; en UPP, una de las protagonistas de la edición, Rym, participó en otro dating show tras salir de este: Mujeres y Hombres y Viceversa (Bulldog Producciones, 2008-...). En LGK, se da un caso paradigmático de autorreferencialidad: Cristo Contreras tiene una primera cita en First Dates, y la segunda se emite como parte del programa analizado.

La cuarta característica de este apartado que es común a los tres programas es la ruptura de la cuarta pared. Tanto en UPP como en LGK, esto ocurre, en primer lugar, durante las declaraciones a cámara de los personajes, que se intercalan en el flujo de acontecimientos, generalmente para acentuar la comicidad en ambos casos. En común con $\mathrm{GH}$, los dos programas tienen, por un lado, la referencia continua a miembros del equipo técnico y artístico del programa y a la infraestructura tecnológica y, por otro, la aparición de hashtags en pantalla para invitar a la audiencia a participar en la conversación generada en las redes sociales. En el caso de GH es destacable la intervención de la audiencia en el transcurso de los acontecimientos. Según explica del Río, directora de la edición analizada, GH no se trata de un producto acabado, sino que es susceptible de modificarse a medida que la audiencia lo demanda. 
Otro de los elementos que alejan al formato de Zeppelin de las otras dos producciones, es el papel que se le otorga a la telepromoción, que aparece tanto presentada por Jorge Javier desde el propio plató de rodaje como en la propia casa, patrocinando la Prueba Semanal que los concursantes deben realizar. Por otra parte, en LGK, al plasmar la vida de cuatro familias gitanas, la aparición de palabras y tradiciones típicas de su cultura ayudan a anclar el programa al referente real.

\subsection{Elementos distanciadores de la realidad}

\subsubsection{Elementos formales de ficción}

En primer lugar, los tres programas presentan tramas principales y subtramas que involucran a los personajes secundarios y protagonistas, como sucede en cualquier narración. Felipe Rodríguez justifica la presencia de estos elementos formales propios de la ficción al apuntar que, pese a que la telerrealidad y la ficción son géneros distintos, ambos cuentan historias, y por eso muchas veces los elementos que las estructuran son los mismos. Subraya también que, en ambos casos, el contenido que se busca explotar es el mismo, la resolución de conflictos. Rodríguez, como diferencia entre ambos géneros, señala que "las tramas y subtramas de la ficción se inventan, y en un reality son realidad". Define su labor como guionista en el sentido de «dar prioridad, es decir, elegir qué tramas se destacan y hacer una guía de lo importante». De este modo, en GH encontramos cinco tramas principales; en UPP, tres, una por cada protagonista; y en LGK, cuatro, una por familia. En los tres casos, el relato tiende a centrarse en un número reducido de tramas y múltiples subtramas o hilos narrativos que las conectan. Esta estructura recuerda, en parte, a la de una telenovela, más aún si se tiene en cuenta la concentración de un elevado número de acontecimientos en un período temporal corto.

En cuanto a los elementos formales propios de la ficción, cabe destacar en los tres programas el trabajo de montaje de las secuencias para organizar los puntos de giro de cada capítulo y de las tramas en general. «No se hacen cambios en las historias, pero sí se ordenan y condensan los hechos para que la audiencia entienda lo mejor posible y se sienta más emocionada y atraída», explica Rodríguez en referencia a las secuencias que componen parte de GH y la totalidad de LGK y UPP.

Al respecto del tipo de narración en estos programas, podemos encontrar una serie de diferencias entre UPP y LGK por un lado y GH por otro. En el caso de los dos primeros programas, la estructura es la de una narración clásica, con planteamiento, nudo y desenlace, de historias que discurren paralelas, aunque en algunos casos las subtramas permitan conectarlas entre sí. En el caso de $\mathrm{GH}$, en cambio, el planteamiento de la narración se basa en la presentación de las historias de manera simultánea, entrelazándose entre ellas, por lo que la labor fundamental del montaje del programa es el de componer un discurso lógico, e intentar siempre que sea realista.

Por otra parte, tanto en UPP como en LGK, aparecen personajes estereotipados, algo que es posible gracias al montaje, en muchos casos, pese a que la esencia de la personalidad del personaje se mantenga. Vicente F. Cabodevila comenta que, mientras que en la ficción los personajes son inventados y la labor del guionista es darles forma, en los realities hay que «investigar mucho a los personajes para saber cuáles son las facetas que te interesa destacar, y luego, como siempre digo, hacemos una especie de caricatura».

\subsubsection{Elementos formales del propio formato}

Pese a ser un formato reciente, el reality show presenta una serie de características formales que suelen ser comunes a los subformatos que engloba. En este caso, hemos localizado tres rasgos comunes a los tres programas analizados. El primero de ellos es la existencia de elementos definitorios de cada programa que se mantienen temporada tras temporada, a los que Noelia del Río se refiere como «elementos de guion de formato» o "estímulos». En el caso de GH y UPP podemos señalar reglas o pruebas impuestas por el programa que los concursantes se comprometen a asumir desde el momento en que deciden formar parte del mismo. LGK, en cambio, cuenta con estímulos de un orden distinto a los mencionados en los casos anteriores. Según explica el director del programa, Eireos, los concursantes hablan con el equipo para expresar sus deseos en su nueva etapa vital para llegar a un acuerdo con estos y a partir de ahí generar las tramas. Para generar estos contenidos, es necesario un guión, aunque sea distinto del de la ficción. Según explica Raúl García, pese a que lo que se ve en pantalla sucede de verdad, «fue provocado previamente».

El segundo lugar común es la presentación formal de los programas que, sea total (LGK, UPP) o parcialmente (GH, donde también hay directo), se realiza a partir de secuencias cortas, de no más de tres minutos, que se disponen de forma dinámica en intervalos periódicos para entretener al espectador. Este esquema recuerda al que sigue el montaje de las ficciones seriadas para televisión.

El tercer elemento coincidente en los tres programas es el uso de flashbacks y flashforwards. Su función fundamental suele ser «cebar», pero a veces también son empleados para situar al espectador o ponerlo en antecedentes. En GH lo habitual es encontrarlos al principio de la emisión a modo de anticipo de lo que sucederá en esa Gala, mientras que en LGK y UPP tenemos un flashback al principio de cada capítulo que resume lo sucedido hasta el momento, avances del propio capítulo intercalados en su transcurso, y «cebos» al final de cada uno, como método para fidelizar a la audiencia.

Además de estos, encontramos otros elementos comunes en LGK y UPP: el uso de la voz off narradora como guía de lo que está sucediendo en el programa (la de Teté Delgado y la de Luján Argüelles, respectivamente), y el uso de rótulos que identifican a través de su nombre y su mote a los personajes que aparecen haciendo sus declaraciones a cámara. Esto último sirve para reforzar el componente cómico de estos dos realities, que no está presente en la misma medida en $\mathrm{GH}$.

\subsubsection{Elementos de contenido}

Los primeros elementos de contenido, comunes a los tres realities, son consecuencia directa de la re-creación de situaciones ya mencionadas. En el caso de GH, podemos destacar varios ejemplos, la mayoría de la primera Gala, en la que a los concursantes se les proporciona la misión de guardar un secreto falso a sus compañeros. También podemos señalar en este apartado las entrevistas en el plató que se realizan a cada uno de los concursantes expulsados, en las que se les ofrece la posibilidad de observar su paso por el concurso y comentarlo con el presentador y los colaboradores presentes en el plató, desencadenando, por lo general, disputas o nuevos conflictos. 
En el caso de UPP y LGK, además del contenido desencadenado por acción del guión de formato, encontramos otros rasgos que podemos mencionar aquí. El primero es la pantomima del cuento de hadas en UPP, y la estructura de fábula de LGK en tanto Teté Delgado suele emitir moralejas al respecto de las historias que nos va relatando. Otro elemento sería el uso de gags potenciados mediante el montaje que, de nuevo, inciden en el humor de ambos programas. El último rasgo es la integración en la diégesis por parte de los personajes de sonidos extradiegéticos e introducidos en postproducción, que de nuevo es común a ambos realities.

\section{Discusión y conclusiones}

\subsection{Reality show, ¿ficción o realidad?}

Tras la investigación realizada, llegamos a la conclusión de que los reality shows no ofrecen la realidad a la que su nombre hace referencia y que supone un gran reclamo para el público, que siente curiosidad por sus semejantes.

Para que las situaciones re-creadas de un reality show resulten realistas, es necesario someter a cierto control a todos los elementos que forman parte de su universo narrativo. Esto, como hemos tratado de reflejar en nuestras fichas de análisis, se lleva a cabo a través de dos tipos de elementos. Por un lado, los formales, que pueden ser de dos tipos: los propios de la ficción (tales como la elaboración de historias con planteamiento, nudo y desenlace, o la creación de puntos de giro a través del montaje); y los propios del formato (como los cambios en el curso de los acontecimientos dados por las reglas establecidas por el programa). En segundo lugar, destacan los elementos de contenido, como las premisas de punto de partida que toman algunos programas, véase el cuento de hadas en UPP. Estos elementos alejan a los reality shows del azar de la realidad, y evidencian que este formato aspira a atraer al público mediante la creación de ciertos componentes de interés que lo acercan a la ficción.

Sin embargo, por próximos que se hallen de la ficción, no forman parte de este género ya que, en cierto modo, en los realities se da lo contrario que en esta: mientras que en la ficción el conflicto se encarna en los actores y se resuelve en escena, los personajes del reality nos hacen partícipes de su propio drama íntimo. Teniendo esto en cuenta, podemos limitar la vinculación del formato con el género ficcional a la vía formal, por el uso de algunas de sus estructuras dada la necesidad de contar historias.

Respecto a la mediación en el reality show, además de la propia de todo discurso audiovisual en tanto existe una intervención humana externa que persigue alguna finalidad, queremos señalar la intervención relacionada con la generación de situaciones. En el reality se preconfigura y re-construye la realidad que constituye el referente, y para poder participar de ella, se niega el referente real. Por tanto, los acontecimientos generados por el programa, aunque sean experimentados realmente por sus protagonistas, no existen fuera del universo televisivo.

En referencia a nuestra primera hipótesis y tomando como referencia los resultados triangulados de nuestro análisis, podemos afirmar que el reality show no es realidad, ni es ficción, sino simulacro (en el sentido baudrillardiano; más real que lo real) e hiperrealidad, en tanto posee su propio universo creado a imagen y semejanza del referente, y este universo requiere ser entendido como parte del medio televisivo, pues no tiene cabida fuera.

\subsection{Una televisión en transformación}

Partiendo de la división aceptada por la mayor parte de la comunidad de investigadores, que se apoya en la división de la evolución del medio televisivo en paleotelevisión (56-80) y neotelevisión (desde los 80), nos gustaría señalar que la situación actual del medio requiere plantearse que tal vez hayamos entrado en una nueva era, o estemos a punto de entrar en ella.

Tal vez este cambio no tenga, por ahora, la misma envergadura que supuso el paso de la era paleo a la neo, lo que impide que podamos hablar de una nueva escisión. Aún así, consideramos que no estamos ante la misma televisión que fue denominada como neotelevisión en los años 80.

Suscribiendo la perspectiva de Gordillo, entendemos la televisión actual como «hipertelevisión», una televisión que recupera las formas previas para exagerarlas, que vive de llevar al extremo aquello que se gestó desde la época neotelevisiva, y que constituye un cambio de tendencia que vendría a confirmar nuestra segunda hipótesis.

Otras de las dos fundamentales características, que señala Gordillo, que podemos encontrar en GH como paradigma de la hipertelevisión, son la autorreferencialidad y la importancia que se atribuye al contenido publicitario.

Cabe destacar también el carácter multiplataforma del programa que, si bien estuvo presente desde los inicios a través de los votos telefónicos del público, se llevó aún más lejos con el desarrollo de las nuevas tecnologías, de modo que en GH 17, la referencia a segundas pantallas es una constante. Así, las plataformas tradicionales se complementan hoy con la app del programa (a través de la cual también se realizan votaciones), blogs de exconcursantes o el uso de hashtags en todas las emisiones semanales del programa para que el público interactúe a través de las redes sociales.

Por lo tanto, desde la primera a la última edición de GH, los realities han crecido, la audiencia ha crecido con ellos, y es muy importante que los asimile como lo que son, ni realidad, ni ficción, sino hiperrealidad y entretenimiento.

El espectador ya no mira igual los reality shows, ya no es inocente, y prueba de ello son los concursantes que nutren hoy los elencos de estos programas, conocedores de las dinámicas televisivas, y más familiarizados que nunca con las cámaras.

Este cambio, tanto en el espectador como en el concursante, deriva de una educación del ojo transmitida por la cultura televisiva, que es perfectamente lógica si se tiene en cuenta que llevamos diecisiete años en contacto con este cambio de paradigma. Lo extraño sería, en todo caso, entender el fenómeno y comportarse ante él como si se estuviese experimentando por primera vez. 


\subsection{Estigmas en torno al formato y adecuación de la recepción}

Pese a sus elevados índices de audiencia, el reality show es un formato estigmatizado. Muchas veces, se le acusa de ser carente de contenido, en el sentido de que la información que transmite no puede, por lo general, otorgar conocimientos al receptor. Los expertos entrevistados que trabajan en el medio aclaran que la función principal de estos programas es acompañar al espectador, y comparan el tipo de información que aportan con la que se puede extraer de una película, y no de un telediario. Consideramos que, en el caso de los programas de entretenimiento, no es un requisito fundamental la transmisión de conocimientos, pues en la actualidad, la función de estos es más evasiva que instructiva.

De los grupos de discusión extrajimos que otro prejuicio que pesa sobre estos programas es que se suele presuponer que sus seguidores no tienen inquietudes más allá del consumo de los mismos. Los expertos también apuntan hacia el respeto por los límites éticos en estos contenidos, y explican la diferencia entre los corporativos, propios de la línea editorial de la cadena, los de la producción ejecutiva del programa y los que marcan los propios personajes, y todos ellos deben ser respetados siempre.

Además del respeto por los límites de la ética, lo fundamental ante estos programas es que el espectador reflexione y comprenda el formato que tiene ante él, en lugar de demandar contenidos culturales y educativos en espacios televisivos cuya función no es la formación de la capacidad crítica de los ciudadanos. Existen otros programas que persiguen tal fin, y que es interesante ofrecer como alternativa o complemento de los anteriores, ya que el consumo de ambas categorías no es incompatible.

En vista a todo lo anterior y con el apoyo de las declaraciones de los entrevistados, confirmaríamos nuestra tercera hipótesis, según la cual los realities son una opción televisiva de entretenimiento tan válida como cualquier otra, y que su consumo no tiene por qué resultar nocivo siempre que se comprenda que aquello aparece en pantalla no es un reflejo de la realidad, sino algo hiperreal, del mismo modo que se asume que una ficción no representa el mundo real.

\subsection{El pacto entre la audiencia y el medio}

Para concluir, y considerando la triangulación de resultados que hemos llevado a cabo con las entrevistas a expertos y los grupos de discusión, queremos llamar la atención sobre una última cuestión que es transversal a todas las tratadas aquí. Consideramos que el problema es que se presuponga que la telerrealidad es realidad en la televisión, cuando verdaderamente es el reflejo de una realidad creada en unas circunstancias especiales, extremas y que no se darían en la vida real, que pasa por componer el discurso de una manera atractiva, con elementos que potencian la aparición de conflictos y situaciones que, si bien suceden realmente, forman parte del espectáculo televisivo.

Este punto de vista nos lleva a considerar la existencia de un pacto comunicativo entre en el espectador de realities y el medio. De este modo, el espectador está dispuesto a permitir la presencia de una cierta ficcionalización en estos formatos, como puede ser la provocación de situaciones o la re-ordenación de los puntos de giro, en tanto son elementos que sirven para crear interés. En el caso del medio, la función que debe desempeñar es la de elaborar una historia que sea verosímil para el público, sin que este se sienta engañado.

En suma, debemos señalar que el interés del público en este tipo de programas, más allá que del grado de guionización o reformulación de la realidad, procede de otros lugares: de la evasión, del entretenimiento que le generan estos formatos. La demanda de reality shows por parte de la audiencia seguirá estando cubierta por el medio, siempre que este continúe elaborando historias que, sin ser verdad, sean verosímiles.

\section{Referencias bibliográficas}

Barlovento Comunicación (2017). Barlovento Comunicación. Disponible en: https://www.barloventocomunicacion.es

Baudrillard, J. (1978). Cultura y simulacro . Barcelona, España: Kairós.

Bauman, Z. (2000). Modernidad líquida . Buenos Aires, Argentina: Fondo de Cultura Económica de Argentina, S.A.

Bignell, J. (2004). An introduction to Television Studies . Londres, Reino Unido.

Bort Gual, I. (2009). La Granhermanización de la Información Televisiva: asimilación de los estilemas del reality show en los procesos del periodismo informativo (Actas del II Congreso Internacional de Teoría y Técnica de los Medios Audiovisuales) Universitat Jaume I, Castellón. Recuperado en: http://repositori.uji.es/xmlui/handle/10234/34026

Cáceres Zapatero, M.D. (2010). El discurso de la televisión en la cultura del espectáculo: los procesos de mediación en los programas de la telerrealidad . Sphera Pública, (10). 207-222. Recuperado en: http://www.redalyc.org/pdf/297/29719345014.pdf

Casetti, F.; Di Chio, F. (1999). Análisis de la televisión, instrumentos, métodos y prácticas de investigación. Barcelona, España: Paidós Ibérica S.A.

Casetti, F.; Odin, R. (1990). De la paléo- à la néo-télévision. Communications , 51(1). 10-24.Recuperado en: http://www.persee.fr/doc/comm 05888018_1990_num_51_1_1767

Castelló Mayo, E. (2004). La producción mediática de la realidad. Madrid, España: Ediciones del Laberinto S.L. (Laberinto).

Chicharro Merayo, M.M. (2008). Información, ficción, telerrealidad y telenovela: algunas lecturas televisivas sobre la sociedad española y su historia. Comunicación y Sociedad, (11). 73-98. Recuperado en: http://www.redalyc.org/pdf/346/34611503004.pdf

Darley, A. (2002). Cultura visual digital. Espectáculo y nuevos géneros en los medios de comunicación. Barcelona, España: Paidós. 
Eco, U. (1986). La estrategia de la ilusión . Madrid, España: Lumen.

Gómez, E.; Ramiro, E. (2005). Gran Hermano 7 : La telerrealidad en tela de juicio. Fòrum de recerca , (11). Recuperado en: http://repositori.uji.es/xmlui/handle/10234/78868

Gordillo Álvarez, I. (2009). La hipertelevisión: géneros y formatos . Quito, Ecuador: Ediciones Ciespal.

Gordillo Álvarez, I. Et al (2011). "Hibridaciones de la hipertelevisión: información y entretenimiento en los modelos de infoentertainment". Revista Comunicación, 1(9). 93-106. Recuperado en: https://idus.us.es/xmlui/handle/11441/25517

Gran Hermano. (2017). Informe corporativo . Recuperado de http://www.mediaset.es/mediasetcom/GH17_MDSFIL20160907_0003.pdf

Imbert, G. (2003). El zoo visual. De la televisión espectacular a la televisión especular. Barcelona, España: Gedisa.

Imbert, G. (2004). De lo espectacular a lo especular (apostilla a La Sociedad del Espectáculo). CIC (Cuadernos de Información y Comunicación) (9), 69-81. Recuperado en: http://revistas.ucm.es/index.php/CIYC/article/viewFile/ClYC0404110069A/7309

Lipovetsky, G. (1986). La era del vacío . Barcelona, España: Anagrama.

Normand Martín, E. (2015). Reality show, ¿ ¿ealidad o ficción? . (Trabajo de Fin de Grado). Facultad de Ciencias Económicas y Empresariales, Alicante. Recuperado en: http://hdl.handle.net/10045/48737

VV (2009). "Estrategias de la transparencia. Imposturas de la comunicación mediática". Santiago de Compostela, España: Universidad de Santiago de Compostela.

"Yo hago los vídeos de Gran Hermano ": Los secretos de la "contadora de historias" desde la primera edición. (2017). Recuperado el 1 de junio, 2017 de http://www.mediaset.es/que_no_salga_de_aqui/Gran-Hermano-secretos-contadora-his torias_2_2321580074.html

\section{Cómo citar este artículo en bibliografías - How to cite this article in bibliographies / references:}

GRELA-BARROS, M. P.; LÓPEZ-PENIDO, X.; PÉREZ-PEREIRO, M. (2018): "La re-creación de la realidad en los «reality shows»". En Revista de la Asociación Española de Investigación de la Comunicación, vol. 5, número 9, pp. 104-111. 